https://helda.helsinki.fi

\title{
Evaluating a novel formula for noninvasive estimation of arterial carbon dioxide during post-resuscitation care
}

Rentola, Raisa R.

2020-10

Rentola , R R , Skrifvars , M B , Heinonen , E , Häggblom , T \& Hästbacka , J 2020 , ' Evaluating a novel formula for noninvasive estimation of arterial carbon dioxide during post-resuscitation care ' , Acta Anaesthesiologica Scandinavica , vol. 64 , no. 9 , pp. 1287-1294 . https://doi.org/10.1111/aas.13652

http://hdl.handle.net/10138/331656

https://doi.org/10.1111/aas.13652

unspecified

acceptedVersion

Downloaded from Helda, University of Helsinki institutional repository.

This is an electronic reprint of the original article.

This reprint may differ from the original in pagination and typographic detail.

Please cite the original version. 


\section{Evaluating a novel formula for noninvasive estimation of arterial}

\section{2 carbon dioxide during postresuscitation care}

3 Short title: Formula for estimating arterial $\mathrm{CO}_{2}$

4

\section{Rentola $\mathrm{R}^{1}$, Skrifvars $\mathrm{MB}^{2}$,Heinonen $\mathrm{E}^{2}$, Häggblom $\mathrm{T}^{3}$, Hästbacka J $\mathrm{J}^{1}$,}

${ }^{1}$ Division of Intensive Care, Department of Anesthesiology, Intensive Care and Pain

8 Medicine, University of Helsinki, and Helsinki University Hospital, Stenbäckinkatu 9

9 PO BOX 100, FI-00029 HUS, Helsinki, Finland

10

${ }^{2}$ Department of Emergency Care and Services, University of Helsinki, and Helsinki University Hospital, Stenbäckinkatu 9 PO BOX 100, FI-00029 HUS, Helsinki, Finland

${ }^{3} \mathrm{GE}$ Clinical Care Solutions, Anesthesia and Respiratory Care, Kuortaneenkatu 2 00510, Helsinki, Finland

Word count: 2988

Corresponding author: Johanna Hästbacka, MD, PhD, University of Helsinki and Helsinki University Hospital Department of Anaesthesiology, Intensive Care and Pain Medicine Haartmaninkatu 4, PB-340, FI-00029 HUS, Helsinki, Finland

Phone: +358504286701

Fax: +358947172368

johanna.hastbacka@hus.fi

\section{Conflicts of interest}

Dr. Markus Skrifvars has received research funding from GE Healthcare and lecture fees from Covidien and BARD Medical (Ireland). Authors Erkki Heinonen and Tom Häggblom are employees of GE Healthcare. 
Abstract

37 Background

Controlling arterial carbon dioxide is paramount in mechanically ventilated patients, and an accurate and continuous noninvasive monitoring method would optimize management in dynamic situations. In this study, we validated and further refined formulas for estimating partial pressure of carbon dioxide with respiratory gas and pulse oximetry data in mechanically ventilated cardiac arrest patients. Methods A total of 4,741 data sets were collected retrospectively from 233 resuscitated patients undergoing therapeutic hypothermia. The original formula used to analyze the data is $\mathrm{PaCO}_{2}$-est1 $=\mathrm{PETCO}_{2}+\mathrm{k}\left[\left(\mathrm{PIO}_{2}-\mathrm{PETCO}_{2}\right)-\mathrm{PaO}_{2}\right]$. To achieve better accuracy, we further modified the formula to $\mathrm{PaCO}_{2}$-est2 $=\mathrm{k}_{1} * \mathrm{PETCO}_{2}+\mathrm{k}_{2} *\left(\mathrm{PIO}_{2}-\mathrm{PETCO}_{2}\right)+\mathrm{k}_{3} *\left(100-\mathrm{SpO}_{2}\right)$. The coefficients were determined by identifying the minimal difference between the measured and calculated arterial carbon dioxide values in a development set. The accuracy of these two methods was compared with the estimation of the partial pressure of carbon dioxide using end-tidal carbon dioxide.

\section{Results}

With $\mathrm{PaCO}_{2}$-est1, the mean difference between the partial pressure of carbon dioxide, and the estimated carbon dioxide was $0.08 \mathrm{kPa}\left(\mathrm{SE} \pm 0.003\right.$ ); with $\mathrm{PaCO}_{2}$-est2 the difference was $0.036 \mathrm{kPa}$ (SE \pm 0.009 ). The mean difference between the partial pressure of carbon dioxide and end-tidal carbon dioxide was $0.72 \mathrm{kPa}(\mathrm{SE} \pm 0.01)$. In a mixed linear model, there was a significant difference between the estimation using end-tidal carbon dioxide and $\mathrm{PaCO}_{2}$-est1 $(p<0.001)$ and $\mathrm{PaCO}_{2}$-est2 $(p<0.001)$, respectively.

\section{Conclusions}

This novel formula appears to provide an accurate, continuous, and noninvasive estimation of arterial carbon dioxide.

62 
67 Monitoring carbon dioxide is paramount in mechanically ventilated patients and commonly performed by measuring the partial pressure of carbon dioxide $\left(\mathrm{PaCO}_{2}\right)$ with arterial blood gas (ABG) analysis. Although an $\mathrm{ABG}$ analysis intermittently provides exact $\mathrm{PaCO}_{2}$ values, $\mathrm{PaCO}_{2}$ may change despite constant ventilation.

End-tidal carbon dioxide generally underestimates arterial $\mathrm{PaCO}_{2}{ }^{1}$ End-tidal carbon dioxide is affected by the ventilation/perfusion ratio ( $V / Q$ ratio), possible cardiac disease such as right-to-left shunt, and increased dead space. ${ }^{2}$ Maintaining normoventilation may be difficult under circumstances where ABG measurements is not available, including prehospital care and patient transport. ${ }^{3}$ The measurement of $\mathrm{PETCO}_{2}$ with continuous capnography is used as a surrogate but may be a poor indicator of $\mathrm{PaCO}_{2}$ because of $\mathrm{V} / \mathrm{Q}$ mismatch. Dyscarbia and unintentional deviation from normoventilation have been associated with poor outcome. ${ }^{4-5}$ Therefore, seeking new dynamic methods to noninvasively estimate $\mathrm{PaCO}_{2}$ is highly important. ${ }^{6}$

We present a method for estimating the $\mathrm{PaCO}_{2}$ level in a continuous and noninvasive way. Previously, we tested a formula for estimating arterial carbon dioxide partial pressures in an experimental model and found good agreement between this formula with measured $\mathrm{PaCO}_{2}$ values in various physiological and pathophysiological conditions. ${ }^{7}$ The formula was developed based on the assumption that the degree of $\mathrm{V} / \mathrm{Q}$ mismatch behind the alveolararterial oxygen tension difference $\left(\mathrm{PA}-\mathrm{aO}_{2}\right)$ is similar for both $\mathrm{O}_{2}$ and $\mathrm{CO}_{2}$. In our previous study, the estimation of $\mathrm{PaO}_{2}$ was evaluated purely under experimental conditions. The

87 primary aim of the present study was to test the agreement of measured $\mathrm{PaCO}_{2}$ and estimated $\mathrm{PaCO}_{2}$ by the original formula in mechanically ventilated cardiac arrest (CA) 
89 patients. The secondary aim was to validate and refine this formula to achieve a better

90 agreement. In addition, we studied whether the accuracy of the current formulas was

91 affected by patient temperatures and the mean arterial blood pressure levels.

92

93

94

95

96

97

98

99

100

101

102

103

104

105

106

107

108

109 


\section{Study subjects and settings}

113 We conducted a retrospective study in mechanically ventilated adult ( $\geqslant 18$ years of age)

114 patients who were treated after CA in a tertiary academic hospital between October 2012 and September 2016. Research approval was obtained from the Hospital District of Helsinki and Uusimaa (HUS/420/2018 25.04.2018).

\section{Collected data}

119 From the hospital laboratory records, we collected the data of temperature-corrected $\mathrm{PaCO}_{2}$ samples taken within the first 48 hours of ICU admission. Physiological data, including

121 respiratory gas values, peripheral oxygen saturation $\left(\mathrm{SpO}_{2}\right)$, and body temperature at the

122 time points corresponding to each ABG sampling, were collected from the ICU electronic

123 patient data management system (Picis, Wakefield, MA, USA). Patient characteristics, such

124 as age, height, weight, and gender, were collected from the ICU electronic patient data

125 management system. Comorbidities and resuscitation factors were collected from electronic patient medical records (Uranus, CGI, Canada). Organ dysfunction and severity of

127 illness scores (Sequential Organ Failure Assessment [SOFA]; the Simplified Acute Physiology

128 Score II [SAPS II]); and the Acute Physiology and Chronic Health Evaluation II [APACHE II]) scores were retrieved from the Finnish Intensive Care Quality Consortium Database (Tieto

130 Healthcare \& Welfare Oy, Espoo, Finland ). ${ }^{8-10}$ 
134 The original formula used for estimating $\mathrm{PaCO}_{2}$ has been published previously and is defined 135 as follows: ${ }^{7}$

$\mathrm{PaCO}_{2}$-est1 $=\mathrm{PETCO}_{2}+\mathrm{k}\left[\left(\mathrm{PIO}_{2}-\mathrm{PETCO}_{2}\right)-\mathrm{PaO}_{2}\right]$

137 where $\mathrm{PETCO}_{2}$ is the measured end-tidal $\mathrm{CO}_{2}$ pressure and $\mathrm{PIO}_{2}$ is the measured inspired $\mathrm{O}_{2}$

138 pressure with the equation of $\mathrm{FIO}_{2} \times$ (barometric pressure-saturated vapor pressure of

$139 \mathrm{H}_{2} \mathrm{O}$ ). $\mathrm{PaO}_{2}$ is estimated from the oxygen dissociation curve. ${ }^{11}$ This formula was developed

140 further in an attempt to improve accuracy. The patient population was divided randomly

141 into derivation and validation groups. Using linear regression, we used derivation data to

142 compose the new, calibrated formula and to determine the calibration factors that would

143 minimize the difference between estimated and measured $\mathrm{PaCO}_{2}$ values.

145 Creation of the calibrated, new formula $\left(\mathrm{PaCO}_{2}\right.$-est2)

146 The relationship factors were defined by fitting the data points for the minimal difference

147 between the blood gas measured $\mathrm{PaCO}_{2}$ and the novel formula estimated value. For this

148 purpose, 6,580 data points measured from the 233 patients were divided into two groups

149 according to $\mathrm{PETCO}_{2}$ values. Data points having $\mathrm{PETCO}_{2}<3 \mathrm{kPa}$ were excluded as potentially

150 artifactual, for example, a leak caused by side-steam gas sampling. The remaining data were

151 randomly allocated to a derivation group of 50 patients. The remaining 183 patients

152 composed the validation group. The 1008 data sets of the derivation group were divided

153 according to a $\mathrm{PETCO}_{2}$ value of $4 \mathrm{kPa}$. The $4 \mathrm{kPa}$ division value was randomly selected to

154 reflect potentially major $(<4 \mathrm{kPa})$ and normal or minor $(\geq 4 \mathrm{kPa}) \mathrm{V} / \mathrm{Q}$ mismatches that could

155 result in different relationship factors. We defined different validation coefficients, called k-

156 factors, for data sets depending on the measured carbon dioxide level, keeping the $4 \mathrm{kPa}$ 
threshold. The potentially major V/Q mismatch group included 255 data sets, and the potentially normal or minor mismatch group included 753 data sets. The remaining data sets $-3,504$ in total-composed the validation group. The study flowchart is presented in Supplementary Figure 1.

162 Using the least square fitting to minimize the difference between the estimated $\mathrm{PaCO}_{2}$ and

$163 \mathrm{ABG} \mathrm{PaCO}_{2}$ values, the equation coefficients were determined for both the major and the normal or minor V/Q mismatch groups separately. These coefficients were then used to calculate the estimated $\mathrm{PaCO}_{2}$ for the validation group data points comprising the presented validation result statistics. The values for the coefficients are presented in Table 1. After adjustments, the formula $\left(\mathrm{PaCO}_{2}\right.$-est2) is defined as follows:

$\mathrm{PaCO}_{2}$ is the arterial $\mathrm{CO}_{2}$ partial pressure, and $\mathrm{PETCO}_{2}$ and $\mathrm{PIO}_{2}$ are the end-tidal $\mathrm{CO}_{2}$ and

170 inspired $\mathrm{O}_{2}$ pressures, respectively, recorded with a side-stream gas analyzer (GE

171 Healthcare, Milwaukee, Wisconsin, USA). $\mathrm{SpO}_{2}$ is the peripheral hemoglobin oxygen

172 saturation measured with a pulse oximeter.

173 The $\mathrm{O}_{2}$ difference in this hypothesis is based on the estimation of $\mathrm{PETO}_{2}-\mathrm{PaO}_{2}$ with the aid

174 of standard bedside monitored parameters. It is well-known that the $\mathrm{O}_{2}$ difference $\left(\mathrm{PIO}_{2}-\right.$

$\left.175 \mathrm{PETO}_{2}\right)$ is approximately PETCO 2 , providing an estimate for $\mathrm{PETO}_{2}\left(\mathrm{PIO}_{2}-\mathrm{PETCO}_{2}\right) .{ }^{12}$

176 Conceptually, this equation is based on the hypothesis that the physiological factors causing

177 the alveolar-arterial tension difference are similar for both $\mathrm{O}_{2}$ and $\mathrm{CO}_{2}$ :

178 ventilation/perfusion mismatch in the form of left-to-right shunt perfusion and alveolar

179 dead-space ventilation. The equation aims to detect the magnitude of these gas exchange 180 disorders. 
181 In shunt perfusion part of the pulmonary artery blood flow is passing the lungs without

182 communicating with the alveoli. In pulmonary vein this shunted blood of venous $\mathrm{O}_{2}$ content

183 mix with the blood flow representing alveolar gas composition. Affinity of low oxygen

184 saturation of the shunted perfusion reduces the mixture oxygen partial pressure from the

185 alveolar equilibrium. Depending on the shunt, the magnitude of dissolved $\mathrm{O}_{2}$ may be

186 insufficient to fully saturate the $\mathrm{Hb}$, which is measured as $\mathrm{SpO}_{2}$ below $100 \%$. The difference

$187\left(100-\mathrm{SpO}_{2}\right)$ measures the magnitude of this insufficiency. Clinician may respond to reduced

$188 \mathrm{SpO}_{2}$ by increasing the $\mathrm{PIO}_{2}$. This compensatory action increases the second term of the

189 equation.

190 In alveolar dead space no gas exchange occurs with the alveolar blood flow, which

191 reduces $\mathrm{SpO}_{2}$. Thus, increase on the term $\left(100-\mathrm{SpO}_{2}\right)$ of the equation indicates the increase

192 in alveolar dead space. Again, clinician may respond to reduced $\mathrm{SpO}_{2}$ by increasing the $\mathrm{PIO}_{2}$

193 increasing respectively the second term of the equation. The gas in alveolar dead space

194 remains in inspired concentrations and dilutes at upper respiratory tract reducing $\mathrm{PETCO}_{2}$.

195 This increases the second term as indication of the alveolar dead space. In addition to a V/Q

196 mismatch, possible differences in $\mathrm{CO}_{2}$ and $\mathrm{O}_{2}$ alveolar exchange may cause additional

197 differences between $\mathrm{PETCO}_{2}$ and $\mathrm{PaCO}_{2}$ not reflected in the $\mathrm{O}_{2}$ difference; for example

198 diffusion disturbance. Each factor was assigned a relationship coefficient, the values of

199 which were determined by the calibration data points.

200

201

Measuring the change in the accuracy of estimation of $\mathrm{PaCO}_{2}$ over time

202 
We divided the 48-hour study period into three-hour intervals; in cases with more than one sample per three-hour period, we calculated the mean of the differences between the measured and estimated $\mathrm{PaCO}_{2}$ values.

206

\section{Statistical analyses}

To validate $\mathrm{PaCO}_{2}$-est 1 and the comparisons used between $\mathrm{PaCO}_{2}$-est2 and $\mathrm{PETCO}$, we calculated the mean difference with the standard deviation (SD) between the measured and estimated $\mathrm{PaCO}_{2}$ values. We assessed the agreement between the measured and estimated $\mathrm{PaCO}_{2}$ values using the Bland-Altman analysis. We used the software created by Olofsen et al. for the Bland-Altman analysis, including the bias with +/-SE and the limits of agreement with $95 \%$ confidence intervals. ${ }^{13}$ Percentage error was calculated from the SD of agreement and mean $\mathrm{CO}_{2}: 100 *\left(1,96 * \mathrm{SD} /\right.$ mean $\left.\mathrm{CO}_{2}\right)$.

Other analyses were performed using Statistical Package for Social Sciences (SPSS), version 25 (IBM SPSS Statistics for Macintosh, Version 24.0. Armonk, NY, IBM Corp.). Withinsubject (WSV) and between-subject variances (BSV), intraclass correlations ( $\tau$ ), and repeatability coefficients were estimated for the differences between estimated $\mathrm{PaCO}_{2}$ and $\mathrm{ETCO}_{2}$. The Bland-Altman method used controls for the effect of repeated measures by calculating the within-subject and between-subject variations. The normality of the distribution of the differences between the measured and estimated values was tested using the Kolmogorov-Smirnov test.

$224 \mathrm{PETCO}_{2}$ was performed using a mixed linear model in which time and measured values were treated as fixed effects, whereas subjects and formulas were treated as random effects. 
226 Also, using a mixed linear model, we tested the accuracy of the formulas over time and

227 whether there was any interaction between the performance of the formulas and the mean

228 arterial blood pressure or patient temperature. We also examined the accuracy of the

229 methods in different $\mathrm{PaCO}_{2}$ and $\mathrm{O}_{2}$ levels by dividing the data in deciles, according to the

230 measured $\mathrm{PaCO}_{2}$ and $\mathrm{FIO}_{2}$ level.

231

232

233

234

235

236

237

238

239

240

241

242 


\section{Results}

244 In total, we included 233 patients and collected 4,741 datasets. The basic patient

245 characteristics are shown in Table 2. We excluded two patients because of missing data for

246 the inspired gas $\mathrm{O}_{2}$ concentrations. The mean number of $A B G$ samples per patient was 15

247 (SD 10). One of the CAs was in the hospital and the other 232 were out of the hospital. All

248 patients were treated with therapeutic hypothermia. Table 3 shows the baseline

249 information about the ventilator parameters and hemodynamics during the 48-hour study

250 period.

251

252 Difference between the estimated and measured $\mathrm{PaCO}_{2}$ values $\left(\mathrm{PaCO}_{2}\right.$-est1)

253 The mean difference between the measured and estimated $\mathrm{PaCO}_{2}$ values $\left(\mathrm{PaCO}_{2}=\mathrm{PETCO}+\mathrm{k}\right.$

$\left.254\left[\mathrm{PIO}_{2}-\mathrm{PETCO}_{2}\right]-\mathrm{PaO}_{2}\right)$ was $0.08 \mathrm{kPa}(\mathrm{SE} \pm 0.003)$. The SD of the differences was 0.62 (SE \pm

255

0.015), percentage error was $24 \%$. The Bland-Altman plot demonstrating the agreement

between the $\mathrm{PaCO}_{2}$-est1 and measured $\mathrm{PaCO}_{2}$ values with limits of agreement and their $95 \%$ confidence intervals is presented in Figure 1.

Intraclass correlation $\left(\mathrm{PaCO}_{2}\right.$-est1)

The within-subject variance for the estimated $\mathrm{PaCO}_{2}\left(\mathrm{PaCO}_{2}\right.$-est1) and measured $\mathrm{PaCO}_{2}$ values was 0.20 ( $S E \pm 0.004)$. The between-subjects variance was 0.19 (SE \pm 0.018$)$. The intraclass correlations ( $\tau=$ ratio of $\mathrm{BSV}$ and total variance) for the estimated $\mathrm{PaCO}_{2}$ and measured $\mathrm{PaCO}_{2}$ values were $\tau 0.48$ (SE \pm 0.025 , Spearman's $\rho-0.105, \mathrm{SE} \pm 0.029$ ). 
267 The data for the $\mathrm{PaCO}_{2}$ values were not normally distributed (Kolmogorov-Smirnov test, $\mathrm{p}$

268 value $<0.001)$. The mean difference between the measured and PaCO2-est2 values was

$2690.036 \mathrm{kPa}(\mathrm{SE} \pm 0.009)$. The SD of the differences was $0.59(\mathrm{SE} \pm 0.06)$, percentage error was

$27023 \%$. The mean difference between the measured $\mathrm{PaCO}_{2}$ and $\mathrm{ETCO}_{2}$ values was $0.71 \mathrm{kPa}(\mathrm{SE}$

$271 \pm 0.010$ ), percentage error was $24 \%$. The SD of the differences was 0.62 (SE \pm 0.07$)$. There

272 was a statistically significant difference between $\mathrm{PaCO}_{2}$-est2 and end-tidal $\mathrm{CO}_{2}$ in estimating

$273 \mathrm{PaCO}_{2}(p<0.001)$. Also, there was a statistically significant difference $(p<0.001)$ when

274 comparing the true and estimated values with the original, unmodified formula $\left(\mathrm{PaCO}_{2}-\right.$

275 est1) and modified formula ( $\mathrm{PaCO}_{2}$-est2).

The Bland-Altman plots demonstrating the agreement between the $\mathrm{PaCO}_{2}$-est2 and measured $\mathrm{PaCO}_{2}$ values, as well as the $\mathrm{PaCO}_{2}\left(\mathrm{PETCO}_{2}\right)$ and measured $\mathrm{PaCO}_{2}$ values with limits of agreement and their 95\% confidence intervals, are presented in Figure $2 \mathrm{a}$ and $2 \mathrm{~b}$, respectively. The accuracy of the $\mathrm{PaCO}_{2}$-est 2 was not affected by the patients' temperature (Supplementary Figure 1). There was no statistically significant difference between the methods at different mean arterial pressure levels (Supplementary Figure 2). $\mathrm{PaCO}_{2}$-est2 was superior to $\mathrm{PaCO}_{2}$-est1a nd end-tidal $\mathrm{CO}_{2}$ at different temperature and blood pressure levels.

The effect of time

The mean difference between the measured $\mathrm{PaCO}_{2}$ values and estimated $\mathrm{PaCO}_{2}$ values in the first three hours was $0.12 \mathrm{kPa}(\mathrm{SE}+/-0.041)$ when using $\mathrm{PaCO}_{2}$-est2. The SD of the differences was 0.73 . The mean difference between the measured and estimated $\mathrm{PCO}_{2}$ 
values changed over time according to the linear mixed model analysis. These changes,

291 however, were not significant $(p=0.06)$. The mean differences between the measured and

292 estimated $\mathrm{PaCO}_{2}$ levels by both methods $-\mathrm{PETCO}_{2}$ and $\mathrm{PaCO}_{2}$-est2-on three-hour intervals

293 starting from the first ABG sample are presented in Figure 3.

294

295

The effect of different carbon dioxide and inspired oxygen levels on the accuracy of

$\mathrm{PaCO}_{2}$-est2

297 Estimations carried out with PaCO2-est2 were the most accurate in normoventilation. The

298 differences between the measured and estimated $\mathrm{PaCO}_{2}$ in $\mathrm{PaCO}_{2}$ deciles are shown in

Figure 4a. The difference between the measured and estimated $\mathrm{PaCO}_{2}$ values was not affected by $\mathrm{FIO}_{2}$ values at the same degree as $\mathrm{PaCO}_{2}$ levels. The differences between the measured and estimated $\mathrm{PaCO}_{2}$ values in $\mathrm{FIO}_{2}$ deciles are shown in Figure $4 \mathrm{~b}$.

302

The intraclass correlation

304 The WSV for the estimated $\mathrm{PaCO}_{2}$ and $\mathrm{ETCO}_{2}$ values were $0.16(\mathrm{SE} \pm 0.004)$ and $0.18 \mathrm{SE}+/-$

$3050.004)$, respectively. The intraclass correlations ( $\tau=$ ratio of BSV and total variance) for the estimated $\mathrm{PaCO}_{2}$ and $\mathrm{PETCO}_{2}$ values were $\tau 0.48$ (SE \pm 0.028 , Spearman's $\rho 0.16, \mathrm{SE} \pm 0.033$ ) and $\mathrm{ETCO}_{2} 0.61$ (SE +/- 0.027, Spearman's $\left.\rho-0.05 \mathrm{SE} \pm 0.034\right)$.

308

309 
315 Discussion

317 We developed and validated a novel formula that utilizes respiratory gas measurements and

$318 \mathrm{SpO}_{2}$ for estimating $\mathrm{PaCO}_{2}$ noninvasively in mechanically ventilated patients. We found a

319 good agreement between measured and estimated $\mathrm{PaCO}_{2}$ values for the novel formula and

320 found no evidence of impaired accuracy depending on patient temperature and mean

321 arterial pressure levels. This formula might enable reliable, noninvasive methods for

322 monitoring mechanical ventilation. The difference between the measured and estimated

$323 \mathrm{PaCO}_{2}$ values in our study is below the limit of agreement of a clinically acceptable $1 \mathrm{kPa}$

324 error. $^{14}$

325 In healthy subjects, there is a reasonable agreement between $\mathrm{PETCO}_{2}$ and arterial

$326 \mathrm{PaCO}_{2}$, especially with temperature corrected $\mathrm{PaCO}_{2} .{ }^{15-16}$ By contrast, with respiratory or

327 cardiac failure, the gap between $\mathrm{PaCO}_{2}$ and $\mathrm{ETCO}_{2}$ widens because of $\mathrm{V} / \mathrm{Q}$ mismatch, which

328 results in lower alveolar and expired breathing gas $\mathrm{CO}_{2}$ levels. In some studies, there has

329 been a strong agreement between $\mathrm{PETCO}_{2}$ and $\mathrm{PaCO}_{2} \cdot{ }^{17-19}$ Other studies have reported that

330 the gradient between $\mathrm{PETCO}_{2}$ and $\mathrm{PaCO}_{2}$ has clinically significant importance considering for

331 example the reliability of monitoring and the adequacy of ventilation. ${ }^{20-21}$ In patients with

332 hypotension and metabolic acidosis, the gap between $\mathrm{PETCO}_{2}$ and $\mathrm{PaCO}_{2}$ is higher than in

333 normotensive and stable patients. ${ }^{22}$

334 The accuracy of the novel formula is the highest in the normoventilation range.

335 Previous studies of end-tidal $\mathrm{CO}_{2}$ and $\mathrm{PtcCO}_{2}$ and show similar results with high $\mathrm{PaCO}_{2}$ levels, 
which can be the result of increased dead space and shunting. ${ }^{22-23}$. The method underestimated the highest $\mathrm{PaCO}_{2}$ values, which may occur with large alveolar dead space.

338 The $\mathrm{PACO}_{2}$ of perfused alveoli equilibrates with blood concentration to maximum venous $\mathrm{CO}_{2}$ concentration independently of the alveolar dead space whereas in the alveolar dead space the concentration remains zero of the inspired gas. At expiration the zero concentration dead space gas dilutes the blood concentration stream from perfused alveoli causing the $\mathrm{PETCO}_{2}$ reduction corresponding to the amount of dead space ventilation. The alveolar dead space effect on oxygen is minor: the $\mathrm{PAO}_{2}$ of the perfused alveoli will decrease more in supplying the whole perfusion with smaller gas volume. During expiration, when mixing in the upper airways, the inspired oxygen concentration from the dead space compensates the reduced $\mathrm{PAO}_{2}$ from the perfused lung regions. As a result of this compensation in oxygenation, the equation is unable to fully compensate the alveolar dead space effect on the $\mathrm{PaCO}_{2}$.

349 Patient temperatures did not affect the formula's accuracy. This is important because patients in prehospital care are more likely to suffer from hypothermia ${ }^{24}$ and targeted temperature management is standard practice during the intensive care of patients after CA. The mean difference between the measured and estimated values was slightly higher in the first three hours compared with the remaining 45 hours but this difference was not statistically significant. In previous studies, the difference between $\mathrm{PETCO}_{2}$ and $\mathrm{PaCO}_{2}$ has been reported to increase over time. ${ }^{25}$ There was a statistically significant difference between the $\mathrm{PaCO}_{2}$ estimates obtained using the two formulas $\left(\mathrm{PaCO}_{2}\right.$-est1 and $\mathrm{PaCO}_{2}$-est2). An improvement regarding $\mathrm{PaCO}_{2}$-est2 compared with $\mathrm{PaCO}_{2}$-est1 is that $\mathrm{PaCO}_{2}$-est2 utilizes data directly from the 
pulse oximeter instead of $\mathrm{PaO}_{2}$ estimated by $\mathrm{SpO}_{2}$ obtained from the oxygen dissociation

361 curve.

In emergency care despite its unreliability for determining the adequacy of ventilation ${ }^{26}, \mathrm{PETCO}_{2}$ is a useful tool in verifying the correct positioning of an endotracheal tube. ${ }^{27}$ Transcutaneous $\mathrm{CO}_{2}$ is routinely used in neonatal ICUs. ${ }^{28}$ In adults, $\mathrm{PtcCO}_{2}$ has shown conflicting results ${ }^{29-30}$ and may be affected by hypotension, peripheral perfusion disturbances and the use of vasoconstrictors. ${ }^{31-32}$ Transcutaneous $\mathrm{PCO}_{2}$ appears to be a more accurate method compared with $\mathrm{PETCO}_{2}$, but its accuracy might deteriorate with extreme $\mathrm{PaCO}_{2}$ values and is also affected by V/Q mismatch. ${ }^{33-34,23}$. There are some limitations to this study. One patient was hemodynamically unstable and potentially had a very low cardiac output (CO). In conditions associated with low CO,

$371 \mathrm{PETCO}_{2}$ does not correlate with $\mathrm{PaCO}_{2}$ values, but unfortunately, the $\mathrm{CO}$ value was not

372 available for assessment in this case. ${ }^{35}$ Our next aim is to identify the limitations of the 373 algorithm and validate the formula in different critically ill mechanically ventilated patient 374 groups.

376 In conclusion the present study shows that a novel formula developed for estimating $\mathrm{PaCO}_{2}$

377 values has good agreement with measured $A B G$ values and outperforms $\mathrm{PETCO}_{2}$ in 378 accuracy. Within certain limits, it offers a noninvasive and continuous method for assessing $379 \mathrm{PaCO}_{2}$. 


\section{Acknowledgments}

382

383 The study was funded with unconditional funding by Helsinki University (three-year

384 research grant 2016-2018, H3702-11-103568, wbs 73702705) and Helsinki University

385 Hospital (State funding, VTR-Y102011094) and research grants from Finska Läkaresällskapet.

386 We want to thank Marcus Norrgård (RN) for their assistance in retrieving the data. The

387 authors also thank Professor Michael Bailey for his contribution to the statistical analyses,

388 and emeritus professor Per Rosenberg for his valuable comments.

389

390

391

392

393

394

395

396

397

398

399

400

401

402 


\section{References}

404

405

1. Hemmati N, Zokaei AH, Karbasforooshan A. Correlation between end-tidal and arterial

406 carbon dioxide partial pressure in patients undergoing craniotomy. J Inj Violence Res 2012;

4074.

408 2. Yamanaka MK, Sue DY. Comparison of arterial-end-tidal PCO2 difference and dead

409 space/tidal volume ratio in respiratory failure. Chest 1987;92:832-5.

410 3. Davis DP, Idris AH, Sise MJ, Kennedy F, Eastman AB, Velky T, et al. Early ventilation and

411 outcome in patients with moderate to severe traumatic brain injury*. Crit Care Med

$412 \quad 2006 ; 34: 1202-8$.

413 4. Helmerhorst HJF, Roos-Blom M-J, van Westerloo DJ, Abu-Hanna A, de Keizer NF, de Jonge

414 E. Associations of arterial carbon dioxide and arterial oxygen concentrations with hospital

415 mortality after resuscitation from CA. Crit Care 2015;19:348.

416 5. Hope Kilgannon J, Hunter BR, Puskarich MA, Shea L, Fuller BM, Jones C, et al. Partial

417 pressure of arterial carbon dioxide after resuscitation from CA and neurological outcome: a

418 prospective multi-center protocol-directed cohort study. Resuscitation 2019;135:212-20.

419 6. Nassar B, Schmidt G. Estimating arterial partial pressure of carbon dioxide in ventilated

420 patients: How valid are surrogate measures? Ann Am Thorac Soc 2017;14:1005-14

421 7. Rentola R, Hästbacka J, Heinonen E, Rosenberg P, Häggblom T, Skrifvars M. Estimation of

422 arterial carbon dioxide based on end-tidal gas pressure and oxygen saturation. J Clin Med

$423 \quad 2018 ; 7: 290$.

424 8. Vincent JL, Moreno R, Takala J, Willatts S, De Mendonca A, Bruining H, et al. The SOFA

425 (Sepsis-related Organ Failure Assessment) score to describe organ dysfunction/failure. On 
426 behalf of the Working Group 1. Intens Care Med 1996;22:707-10.

427 9. Le Gall JR, Lemeshow S, Saulnier F. A new Simplified Acute Physiology Score (SAPS II)

428 based on a European/North American multicenter study. JAMA 1993;270:2957-63.

429 10. Knaus WA, Draper EA, Wagner DP, Zimmerman JE. APACHE II: a severity of disease 430 classification system. Crit Care Med 1985;13:818-29.

431 11. Aaron S. Nunn's applied respiratory physiology, 5th ed. ; Butterworth-Heinemann, 432 Oxford, 2003.

433 12. Subramani S, Kanthakumar P, Maneksh D, Sidharthan A, Rao SV, Parasuraman V, et al.

$434 \mathrm{O}_{2}-\mathrm{CO}_{2}$ diagram as a tool for comprehension of blood gas abnormalities. Adv Physiol Educ $435 \quad 2011 ; 35: 314-20$.

13. Olofsen E, Dahan A, Borsboom G, Drummond G. Improvements in the application and reporting of advanced Bland-Altman methods of comparison. J Clin Monit Comput 2015; 29:127-39.

14. Bendjelid K, Schütz N, Stotz M, Gerard I, Suter PM, Romand J-A. Transcutaneous PCO2 monitoring in critically ill adults: clinical evaluation of a new sensor. Crit Care Med 2005;

$441 \quad 33: 2203-6$.

442 15. Schmitz BD, Shapiro BA. Capnography. Respir Care Clin of N A, 1995; 1:107-17.

443 16. Losa-Reyna J, Torres-Peralta R, Henriquez JJ, Calbet JA. Arterial to end-tidal Pco2

444 difference during exercise in normoxia and severe acute hypoxia: importance of blood

445 temperature correction. Physiol Rep. 2015;3(10):e12512. doi:10.14814/phy2.12512

446 17. Wu C-H, Chou H-C, Hsieh W-S, Chen W-K, Huang P-Y, Tsao P-N. Good estimation of

447 arterial carbon dioxide by end-tidal carbon dioxide monitoring in the neonatal intensive care 448 unit. Pediatr Pulm 2003;35:292-5.

449 18. McSwain SD, Hamel DS, Smith PB, Gentile MA, Srinivasan S, Meliones JN, et al. End-tidal 
and arterial carbon dioxide measurements correlate across all levels of physiologic dead

451

452

453

454

455

456

457

458

459

460

461

462

463

464

465

466

467

468

469

470

471

472

473 space. Respir Care 2010;55:288-93.

19. Takano Y, Sakamoto O, Kiyofuji C, Ito K. A comparison of the end-tidal $\mathrm{CO}_{2}$ measured by portable capnometer and the arterial PCO2 in spontaneously breathing patients. Resp Med 2003;97:476-81.

20. Husaini J, Choy YC. End-tidal to arterial carbon dioxide partial pressure difference during craniotomy in anaesthetised patients. Med J Malaysia 2008;63:384-7.

21. Belpomme V, Ricard-Hibon A, Devoir C, Dileseigres S, Devaud ML, Chollet C, et al. Correlation of arterial Pco2 and Petco2 in prehospital controlled ventilation. Am Journal Emerg Med 2005;23:852-9.

22. Lee S-W, Hong Y-S, Han C, Kim SJ, Moon SW, Shin JH, et al. Concordance of end-tidal carbon dioxide and arterial carbon dioxide in severe traumatic brain injury. $J$ Traum 2009;67:526-30.

23. Ruiz Y, Farrero E, Córdoba A, González N, Dorca J, Prats E. Transcutaneous carbon dioxide monitoring in subjects with acute respiratory failure and severe hypercapnia. Respir Care 2016;61:428-33.

24. Haverkamp FJC, Giesbrecht GG, Tan ECTH. The prehospital management of hypothermia - an up-to-date overview. Injury 2018;49:149-64.

25. Seguin P, Bleichner JP, Branger B, Guillou YM, Feuillu A, Mallédant Y. The measurement of end-tidal carbon dioxide (PETCO2) is not a significant parameter to monitor in patients with severe traumatic brain injury. Can J Anaesth 2001;48:396-400.

26. Prause $G$, Hetz $H$, Lauda $P$, Pojer $H$, Smolle-Juettner F, Smolle J. A comparison of the endtidal- $\mathrm{CO}_{2}$ documented by capnometry and the arterial pCO2 in emergency patients.

Resuscitation 1997;35:145-8. 
474 27. Varon AJ, Morrina J, Civetta JM. Clinical utility of a colorimetric end-tidal $\mathrm{CO}_{2}$ detector in 475 cardiopulmonary resuscitation and emergency intubation. Journal of Clinical Monitoring $476 \quad 1991 ; 7: 289-93$.

477 28. Tobias JD, Wilson WR Jr, Meyer DJ. Transcutaneous monitoring of carbon dioxide 478 tension after cardiothoracic surgery in infants and children. Anesth Analg 1999;88:531-4. 479 29. Gancel P-E, Roupie E, Guittet L, Laplume S, Terzi N. Accuracy of a transcutaneous carbon 480 dioxide pressure monitoring device in emergency room patients with acute respiratory 481 failure. Intensive Care Med 2011;37:348-51.

482 30. Sanders MH, Kern NB, Costantino JP, Stiller RA, Studnicki K, Coates J, et al. Accuracy of 483 end-tidal and transcutaneous PCO2 monitoring during sleep. Chest 1994;106:472-83. 31. Clark JS, Votteri B, Ariagno RL, Cheung P, Eichhorn JH, Fallat RJ, et al. Noninvasive 485 assessment of blood gases. Am Rev Respir Dis 1992;145:220-32. 32. Santos L, Varon J, Pic-Aluas L, Combs AH. Practical uses of end-tidal carbon dioxide monitoring in the emergency department. J Emerg Med 12:633-44. monitors are more accurate than end-tidal monitors. J Anesth 2009;23:198-202. monitoring in the anesthesia of obese patients undergoing laparoscopic bariatric surgery. PLOS ONE 2014;9. and limits. Resuscitation 1994;27:1-8. 
Table 1. Coefficients $k 1, k 2$, and $k 3$ for Formula 2 as determined by using 500 randomly selected data points. The coefficients were created separately for the low and high $\mathrm{PETCO}_{2}$ groups.

\begin{tabular}{l|l|l|l|}
\hline & $\mathrm{k}_{1}$ & $\mathrm{k}_{2}$ & $\mathrm{k}_{3}$ \\
\hline $\mathrm{PETCO}_{2}$-low $(<4 \mathrm{kPa})$ & 1.178 & 0.0132 & 0.0185 \\
\hline PETCO $_{2}$-high $(\geq 4 \mathrm{kPa})$ & 1.049 & 0.0162 & 0.0139 \\
\hline
\end{tabular}

505

506

507

508

509

510

511

512

513

514

515 
Table 2. Characterization of patients and various subgroups of interest

\begin{tabular}{l|l}
\hline Patient characteristics & $62(52-67)$ \\
Age, years & $181(81)$ \\
Male sex, $\mathrm{n}(\%)$ & $179(172-183)$ \\
Height, cm & $85(75-90)$ \\
Weight, kg & \\
Initial rhythm, $n$ (\%) & $228(97.9)$ \\
VF & $2(0.85)$ \\
VT & $2(0.85)$ \\
PEA & $1(0.4)$ \\
Asystole & $20(15-25)$ \\
ROSC, min & \\
Scoring model, $n$ (IQR) & \\
APACHE II & $25(18-31)$ \\
SAPS & $47(35-64)$ \\
SOFA & $8(7-10)$ \\
Prevalence of lung disease, no (\%) & \\
Asthma & $18(7.7)$ \\
COPD & $11(4.7)$ \\
Interstitial lung disease & $2(0.85)$ \\
\hline
\end{tabular}

519

520

521

522 
523 Table 3. Characteristics of ventilation and hemodynamic variables during first and second

524 intensive care unit (ICU) treatment days. Data are shown as median (interquartile range).

\begin{tabular}{lll}
\hline & \multicolumn{1}{c}{ Day 1} & \multicolumn{1}{c}{ Day 2 } \\
$\mathrm{FIO}_{2}, \%$ & $35(30-49)$ & $35(30-45)$ \\
$\mathrm{SpO}_{2}, \%$ & $99(98-100)$ & $99(97-99)$ \\
$\mathrm{PEEP}, \mathrm{cmH}_{2} \mathrm{O}$ & $7(6-8)$ & $7(6-8)$ \\
$\mathrm{HR}$ & $55(45-68)$ & $66(55-79)$ \\
$\mathrm{MAP}, \mathrm{mmHg}$ & $78(73-86)$ & $77(72-84)$ \\
$\mathrm{PETCO}_{2}, \mathrm{kPa}$ & $4.2(3.8-4.7)$ & $4.6(4.1-5.1)$ \\
$\mathrm{PaCO}_{2}, \mathrm{kPa}$ & $5.0(4.5-5.4)$ & $5.2(4.9-5.6)$ \\
$\mathrm{PaO}_{2} / \mathrm{FIO}_{2}$-ratio & $210(36-303)$ & $198(36-310)$ \\
\hline
\end{tabular}

525

526 
527 Figure 1. The Bland-Altman plot assessing agreement between $\mathrm{PaCO}_{2}\left(\mathrm{PaCO}_{2}\right.$-est1) and 528 measured $\mathrm{PaCO}_{2}$

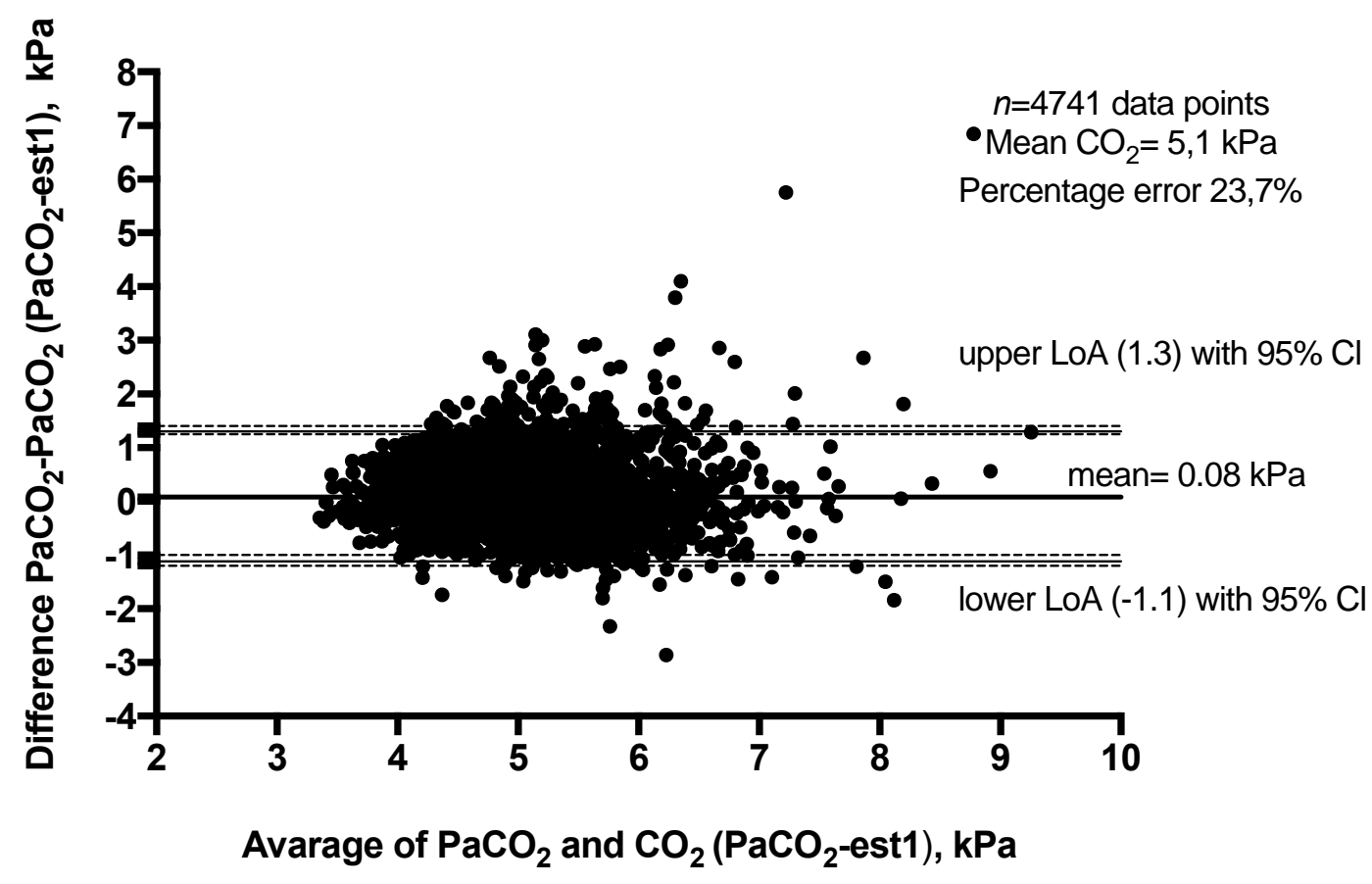

530

531

532

533 
534 Figure 2a. The Bland-Altman plot assessing agreement between $\mathrm{PaCO}_{2}\left(\mathrm{PaCO}_{2}\right.$-est2) and 535 measured $\mathrm{PaCO}_{2}$

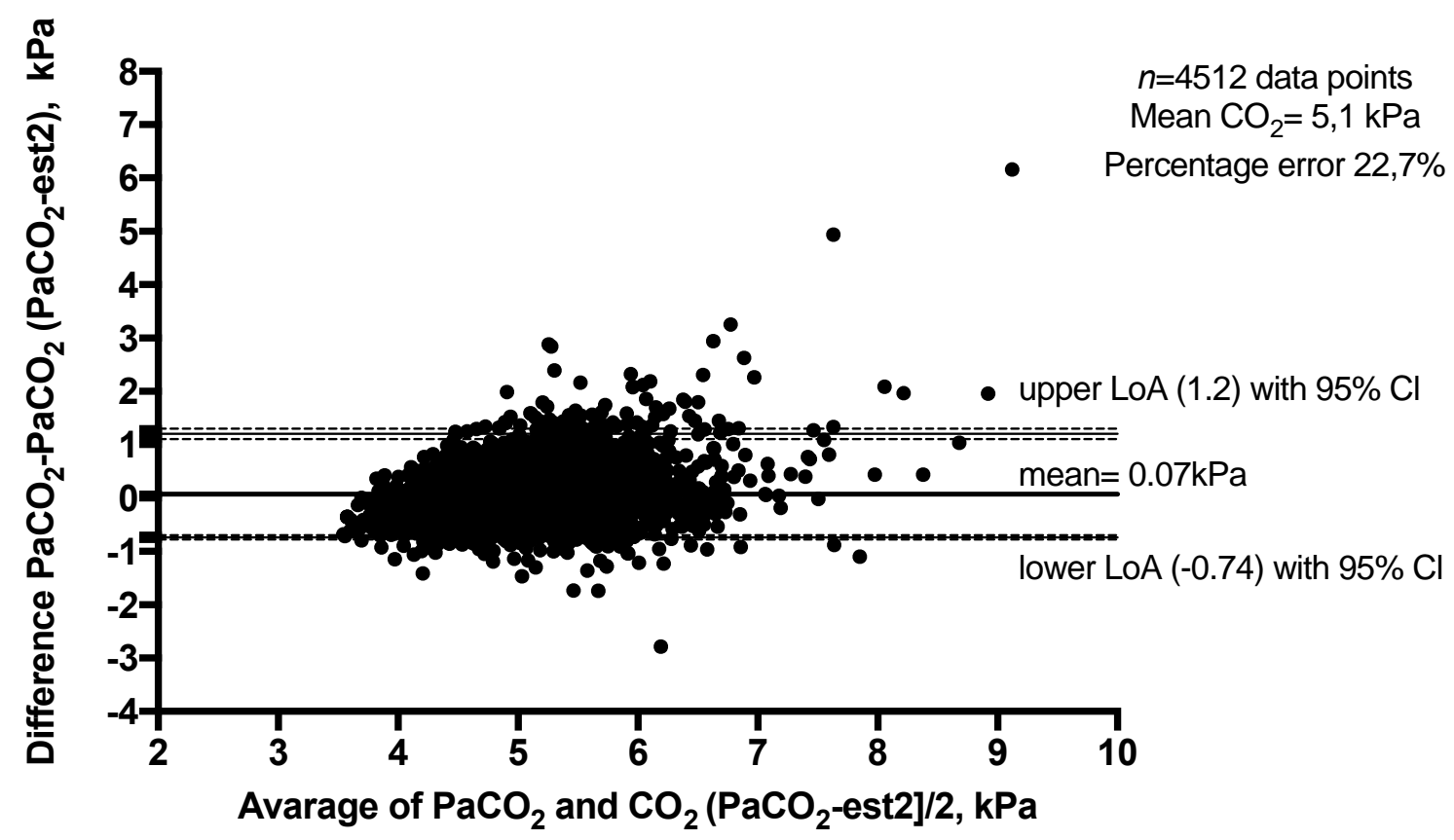


538 Figure $\mathbf{2 b}$. The Bland-Altman plot assessing agreement between $\mathrm{ETCO}_{2}$ and measured $\mathrm{PaCO}_{2}$

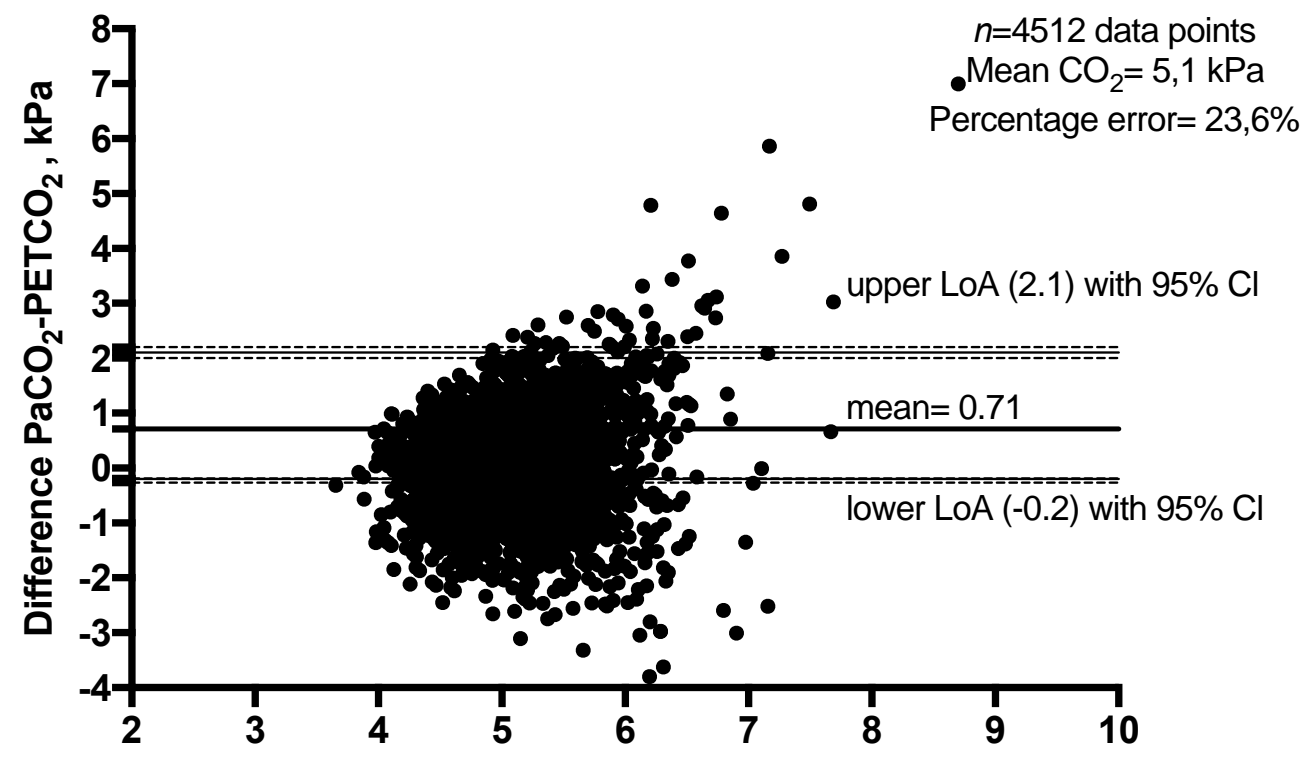


541 Figure 3. The mean differences between measured $\mathrm{PaCO}_{2}$ and estimated $\mathrm{PaCO}_{2}$, and mean

542 differences between measured $\mathrm{PaCO}_{2}$ (Formula 2) and end-tidal $\mathrm{CO}_{2}$ at different time

543 periods

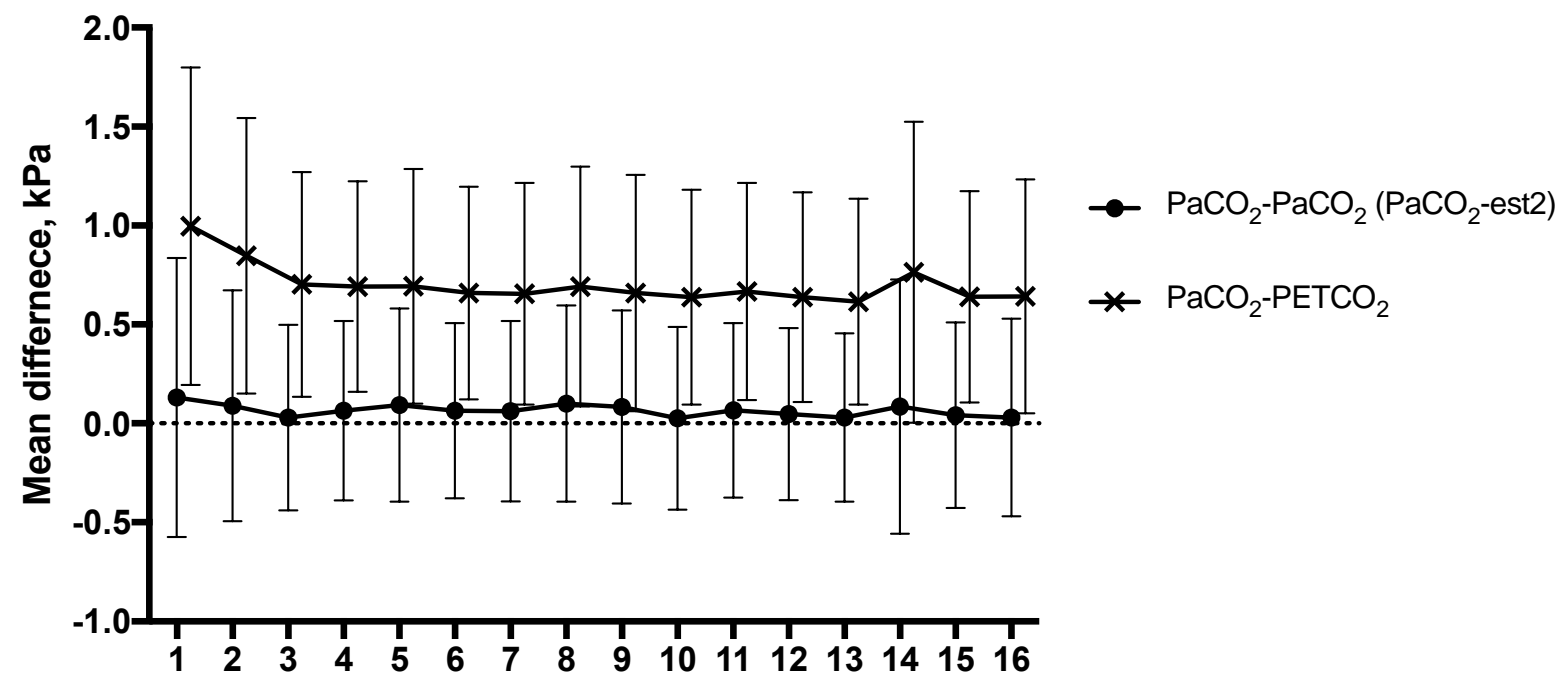

544

Time periods

545 
546 Figure 4a. The mean differences between measured $\mathrm{PaCO}_{2}$ and estimated $\mathrm{PaCO}_{2}$ (Formula

547 2) , and mean differences between measured $\mathrm{PaCO}_{2}$ and end-tidal $\mathrm{CO}_{2}$ at $\mathrm{CO}_{2}$ deciles

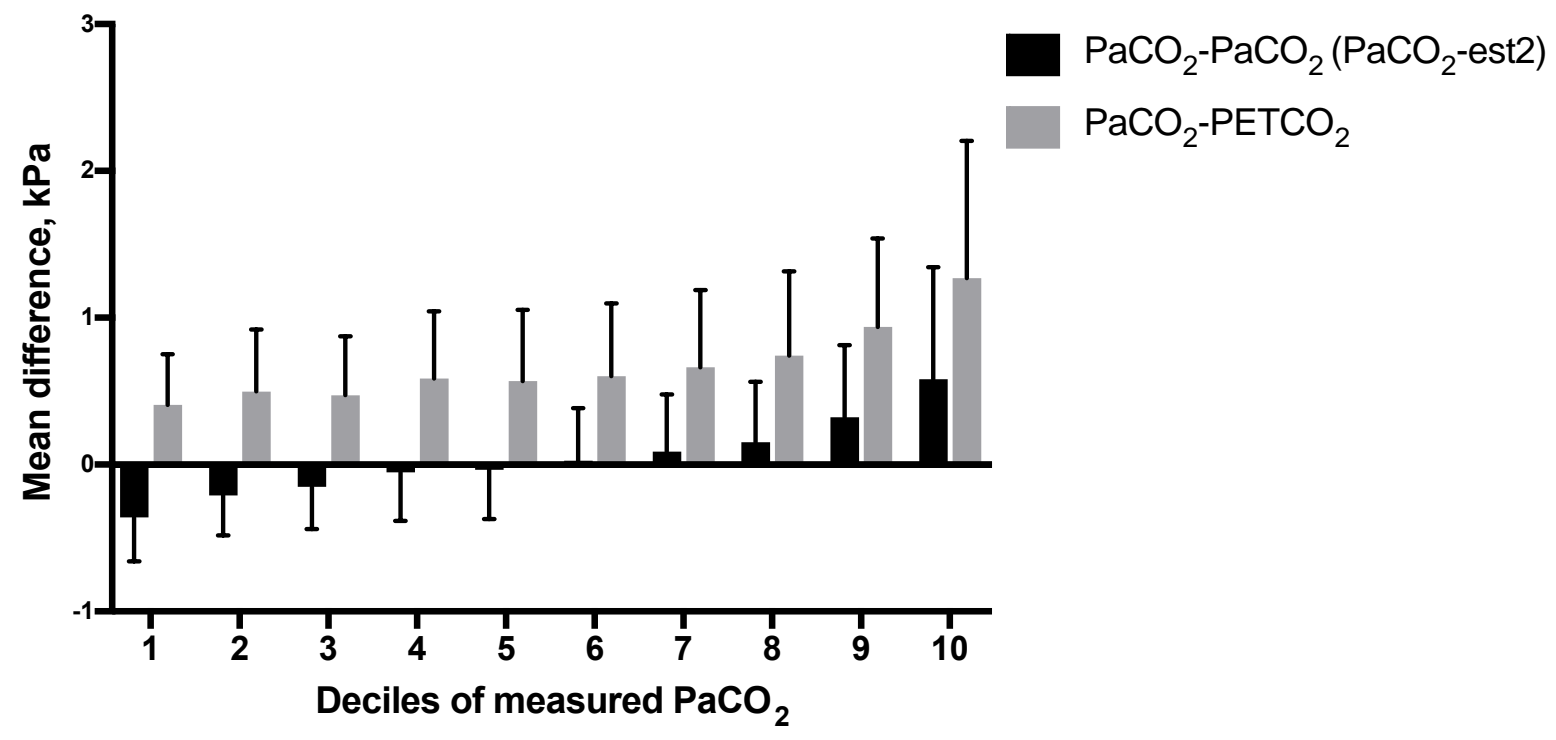


550 Figure 4b. The mean differences between measured $\mathrm{PaCO}_{2}$ and estimated $\mathrm{PaCO}_{2}$ (Formula

551 2), and mean differences between measured $\mathrm{PaCO}_{2}$ and end-tidal $\mathrm{CO}_{2}$ at $\mathrm{FIO}_{2}$ deciles

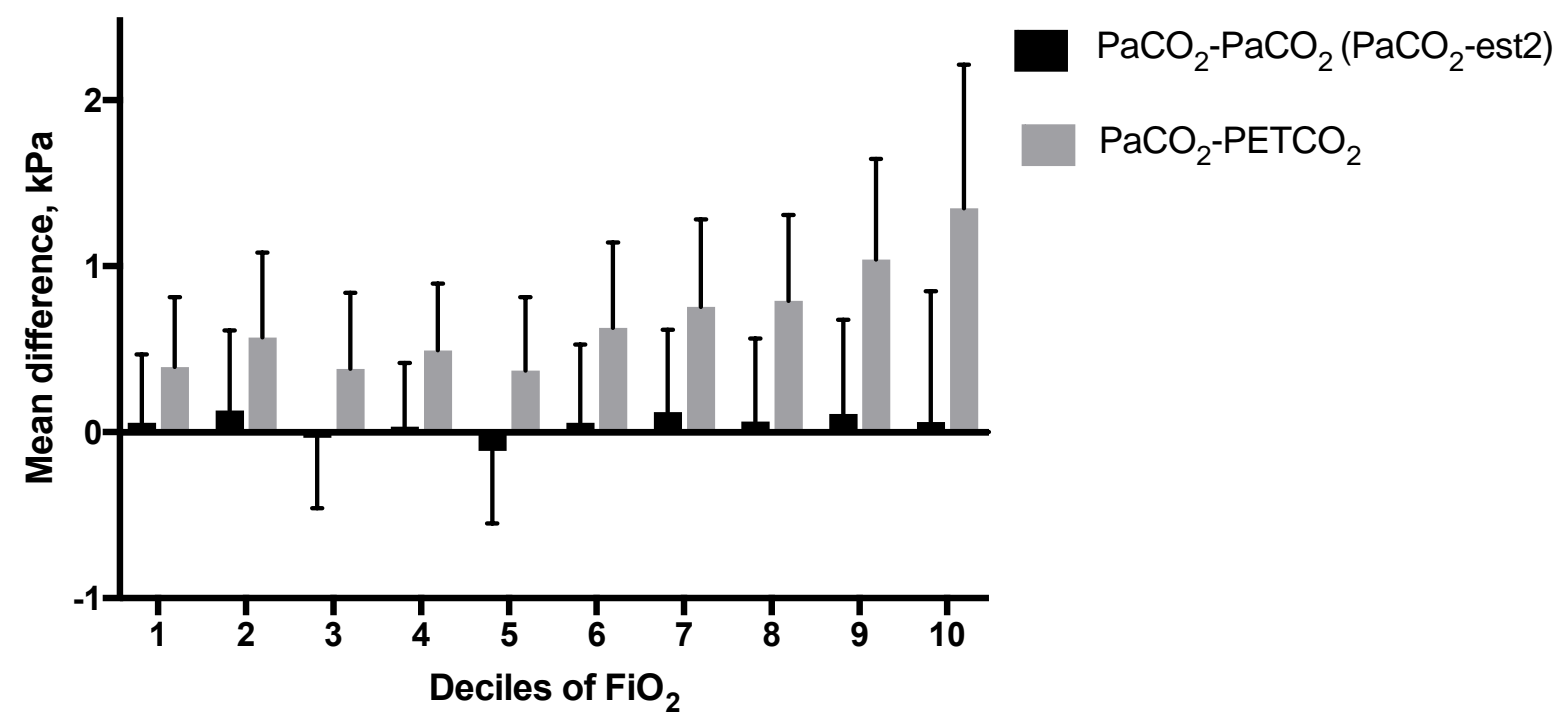

552 


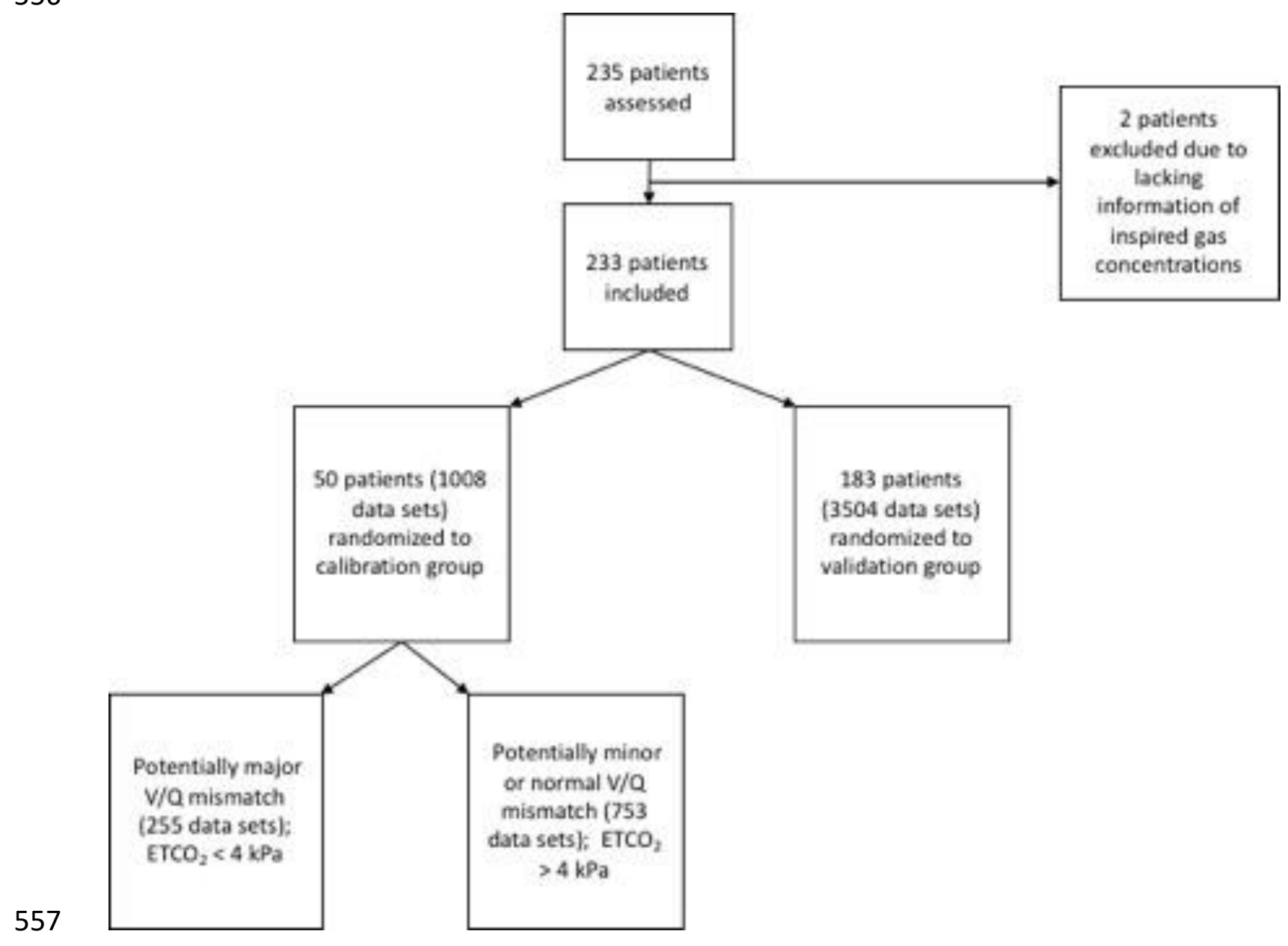


1. Supplementary Figure 2. The difference between measured and estimated $\mathrm{PaCO}_{2}$ at different body temperatures.

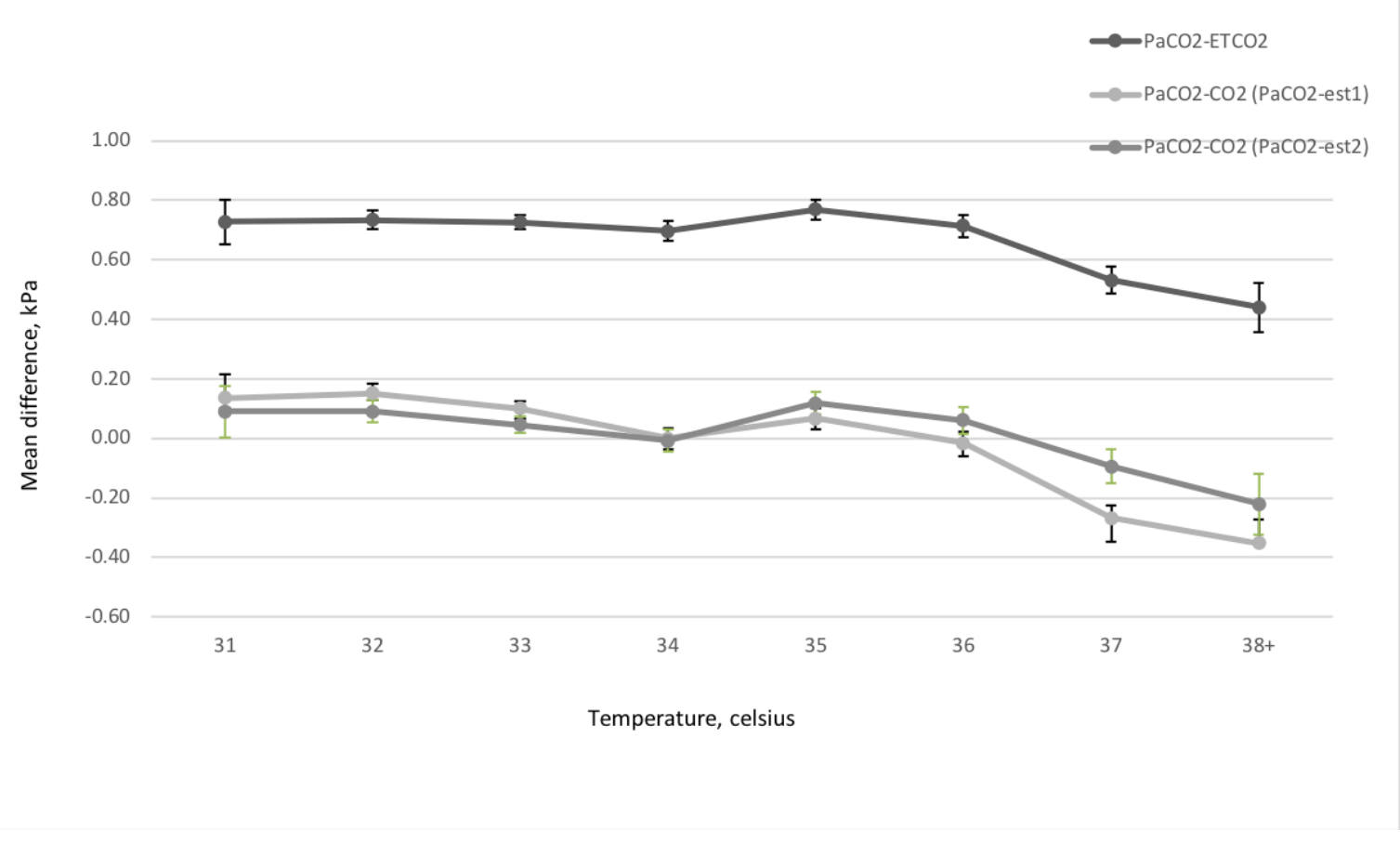


562

563

564

565

2. Supplementary Figure 3. The mean differences between measured and estimated $\mathrm{PaCO}_{2}$ ( Formula 1, Formula 2, and end-tidal $\mathrm{CO}_{2}$ ) at different mean arterial pressure levels.

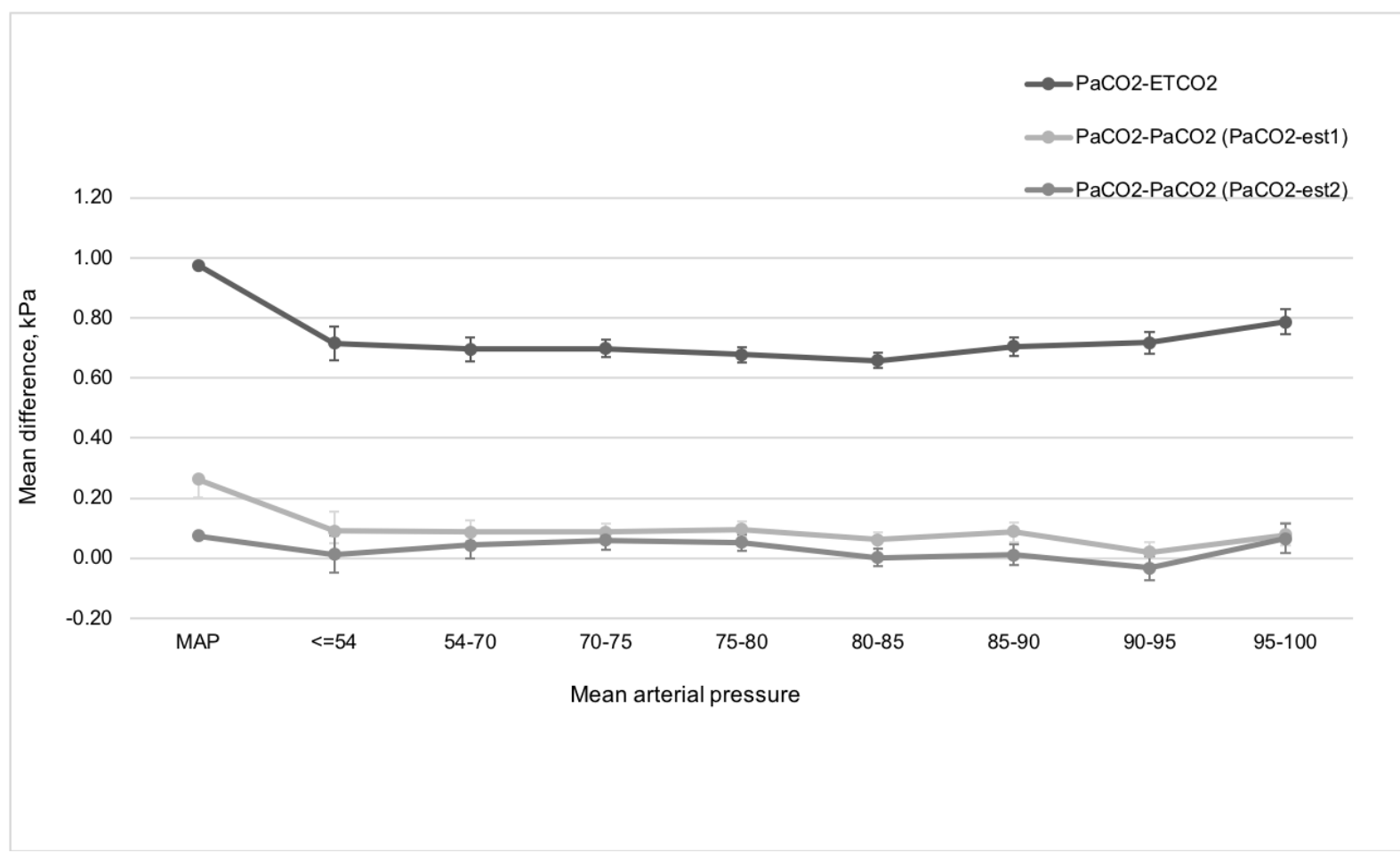

567

568 
570 Table 2 .Patients' characteristics and pre-hospital variables. All continuous values are given

571 as medians (interquartile range), and categorical values as percentages. $\mathrm{Cm}=$ centimeters,

572 kg=kilograms, VF=ventricular fibrillation, VT=ventricular tachycardia, $\mathrm{PEA}=$ pulseless

573 electrical activity, ROSC=Return of spontaneous circulation, COPD= chronic obstructive

574 pulmonary disease

575 Table 3. Hemodynamic variables and variables of ventilator settings and derived data. All

576 continuous values are given as medians (interquartile range). $\mathrm{FIO}_{2}=$ fraction of inspired

577 oxygen, $\mathrm{SpO}_{2}=$ partial oxygen saturation of the arterial blood, $\mathrm{PEEP}=$ positive end-expiratory

578 pressure, $\mathrm{HR}=$ heart rate, $\mathrm{MAP}=$ mean arterial pressure; etCO2=end-tidal carbon dioxide;

$579 \mathrm{PaCO}_{2}=$ arterial partial pressure of carbon dioxide; $\mathrm{PaO}_{2} / \mathrm{FIO}_{2}=$ arterial oxygen partial

580 pressure/fractional inspired oxygen ratio

581

582

583 Figure 1. Bland-Altman plots with $95 \%$ limits of agreement with $95 \%$ confidence intervals

584 demonstrating agreement between partial pressure of carbon dioxide, $\mathrm{PaCO}_{2}$ (Formula 1), and measured $\mathrm{PaCO}_{2}$ during the first 48 hours after admission to the ICU.

586

587 Figures $\mathbf{2 a}$ and $\mathbf{2 b}$. Bland-Altman plots with $95 \%$ limits of agreement with $95 \%$ confidence 588 intervals demonstrating agreement between the $\mathrm{PaCO}_{2}$ (Formula 2) and measured $\mathrm{PaCO}_{2}$

589 values (a) and the $\mathrm{ETCO}_{2}$ and measured $\mathrm{PaCO}_{2}$ values (b) during the first 48 hours after 590 admission to the ICU. 
592

593

594

595

596

597

598

599

600

601

602

603

604

605

606

607

608

609

610

611 Supplementary Figure 2. The difference between the measured and estimated $\mathrm{PaCO}_{2}$ values

612 at different body temperatures. $\mathrm{PaCO}_{2}=$ Partial pressure of arterial carbon dioxide;

$613 \mathrm{ETCO}_{2}=$ end-tidal carbon dioxide.

Figure 3. Mean differences between the measured and estimated $\mathrm{PaCO}_{2}$ values and between measured $\mathrm{PaCO}_{2}$ and end-tidal $\mathrm{CO}_{2}$ at different time points: First time period: 0-3 hours; 2 nd: 3-6 hrs; 3rd 6-9 hrs; 4th 9-12 hrs; 5th 12-15 hrs, 6th 15-18 hrs; 7th 18-21 hrs; 8th: 21-24 hrs; 9th: 24-27 hrs; 10th 27-30 hrs; 11th 30-33 hrs; 12th: 33-36 hrs; 13th: 3639 hrs; 14th: 39-42 hrs; 15th: 42-45 hrs; and 16th: 45-48 hrs.

Figures $4 \mathbf{a}$ and 4 b. The mean differences between measured $\mathrm{PaCO}_{2}$, estimated $\mathrm{PaCO}_{2}$ (Formula 2) and end-tidal $\mathrm{CO}_{2}$ values at different levels of $\mathrm{PaCO}_{2} .1: \mathrm{PaCO}_{2}<4.3 \mathrm{kPa} ; 2$ : $\mathrm{PaCO}_{2}$ 4.3-4.5 kPa; 3: $\mathrm{PaCO}_{2}$ 4.6-4.7 kPa; 4: $\mathrm{PaCO}_{2}$ 4.8-4.9 kPa; 5: $\mathrm{PaCO}_{2}$ 5.0-5.1 kPa; 6: $\mathrm{PaCO}_{2}$ 5.2 kPa; 7: $\mathrm{PaCO}_{2}$ 5.3-5.4 kPa; 8: $\mathrm{PaCO}_{2}$ 5.5-5.6 kPa; 9: $\mathrm{PaCO}_{2}$ 5.7-5.9 kPa; and 10: $\mathrm{PaCO}_{2}>$ $5.9 \mathrm{kPa}$. The mean differences between the measured $\mathrm{PaCO}_{2}$, estimated $\mathrm{PaCO}_{2}$ (Formula 2), and end-tidal $\mathrm{CO}_{2}$ values at different levels of $\mathrm{FIO}_{2}(\%)$. 1: $\mathrm{FIO}_{2}<26 ; 2: \mathrm{FIO}_{2} 26-30 ; 3: \mathrm{FIO}_{2}$ 30-30.3; 4: $\mathrm{FIO}_{2} 30.3-34.6 ; 5: \mathrm{FIO}_{2} 34.6-35.2 ; 6: \mathrm{FIO}_{2} 35.2-40.0 ; 7: \mathrm{FIO}_{2}$ 40.0-45.0; 8: $\mathrm{FIO}_{2}$ 45.0-50.33; 9: $\mathrm{FIO}_{2}$ 50.33-60.55; and $10 \mathrm{FIO}_{2}>60.55$.

Supplementary Figure 1. Flowchart of the study population. V/Q mismatch=ventilation/perfusion mismatch; $\mathrm{ETCO}_{2}=$ end-tidal carbon dioxide; $\mathrm{kPa}=\mathrm{kilopascal}$ 614 
615 Supplementary Figure 3. The mean differences between the measured and estimated

$616 \mathrm{PaCO}_{2}$ values (Formula 1, Formula 2, and end-tidal $\mathrm{CO}_{2}$ ) at different mean arterial pressure

617 levels. $\mathrm{PaCO}_{2}=$ Partial pressure of arterial carbon dioxide; $\mathrm{ETCO}_{2}=$ end-tidal carbon dioxide.

618

619

620 